\section{A Critical Review of the Differential Diagnosis of Root Fracture Line in CBCT scans}

\author{
Mike R. Bueno (D) 1, Bruno Correa Azevedo(D) 2, Carlos Estrela (D) 3.
}

\begin{abstract}
The objective of this critical review of literature is to discuss relevant clinical factors associated with root fractures (RF) visualized by using a new CBCT software. RF constitutes a common occurrence and a challenge in clinical practice, in which the diagnosis becomes essential for the definition of rapid and precise decision-making. The characterization of RF may involve different aspects, such as orientation of the fracture line (horizontal, vertical, oblique), root position of the fracture (cervical, middle, apical third), fracture's coronalradicular position (coronary, coronal-radicular, radicular), continuity of the fracture (crack, incomplete fracture, complete), bone extension of the fracture (supraosseous, bone level, infraosseous fracture). Imaging examinations have been routinely used to aid in the RF diagnosis. Even with high-resolution conebeam computed tomography (CBCT) scans, many doubts often remain about the diagnostic outcome. Many interferences in the analysis of image quality to determine the diagnosis are identified, such as the sharpness, the noise, light and dark artifacts, among others. The professional's knowledge is essential for identifying the different patterns of fracture lines and their repercussions on adjacent bone tissues, as well as for the analysis of artifacts that may hide or show similarities to fracture lines. Fractures lines and root fractures that may be associated with phantom conditions that mimic fractures should be carefully analyzed. CBCT is the exam indicated to identify a root fracture. It is also added to the success of the diagnosis that the professional has scientific knowledge, training and mastery of advanced CBCT software.
\end{abstract}

${ }^{1}$ CROIF Oral Radiology Center, Cuiabá, MT, Brazil

${ }^{2}$ University of Louisville, School of Dentistry, Oral Radiology Department, Louisville, KY, USA

${ }^{3}$ Professor of Endodontics, Federal University of Goiás, Goiânia, Brazil

Correspondence: Professor Mike R Bueno CROIF - Odontologia Diagnóstica Av. Gen. Ramiro de Noronha, 237 Jardim Cuiabá - Cuiabá - MT CEP: 78043-272 Phone: +55-65-36232233 e-mail: mike@croif.com.br

\title{
Introduction
}

An important achievement of endodontics was the benefits acquired with the incorporation of the cone-beam computed tomography (CBCT) exam in clinical practice. The known limitations of periapical radiographs in clinical diagnoses have encouraged professionals to recommend CBCT imaging exams. In this sense, root fractures are conditions that require urgent care with frequent occurrences in clinical practice, in which the correct diagnosis is essential for defining therapeutic decision-making. Studies (1-46) have sought to better structure the process of diagnosis and treatment of this complex clinical condition, which may be associated with local trauma or even more complex traumatic dental injury (TDI).

Root fractures are responsible for injuries to the dentin and cementum, in the periodontal ligament, and in some moments, it may be associated with fractures of the alveolar bone cortical. The characterization of the radicular fracture may involve different aspects, such as the orientation of the fracture line (direction), the location regarding the third, the location regarding the structures involved, the continuity of the fracture, the extension regarding the bone involvement (42-44). Root fractures are fundamentally diagnosed in imaging exams. In clinical conditions associated with TDI, the clinical characteristics may be similar to extrusive and lateral dislocations. Diagnosis by radiographic imaging is facilitated by the direction that is generally oblique in the fracture line, however, it may not be identified soon after the TDI, even with multiple exposures $(43,44)$.

Root fractures represent one of the important diagnostic challenges in dentistry. Even with highresolution cone beam computed tomography (CBCT), many doubts often remain as to the diagnostic outcome. The impact on the correct diagnosis of radicular fracture is generally associated with the decision between extracting or keeping the tooth (7). There are many interferences in the analysis of image quality to determine the diagnosis, such as the sharpness of the images, the presence of noise, light and dark artifacts, among others $(15,34)$.

The professional's knowledge and competence are essential for recognizing the different patterns of fracture lines and their repercussions on adjacent bone tissue, as well as for the analysis of 
artifacts that may hide or present similarities to fracture lines. The objective of this critical review of literature is to discuss relevant clinical factors associated with root fractures visualized by using a new CBCT software.

\section{Periapical radiography and CBCT scans}

Periapical radiographs show markedly limited images for diagnosing root fractures. For the image of the radicular fracture to appear visible on the periapical radiograph, the direction of the fracture must coincide with the angle of the incident $x$-ray beam, which in most cases this fact does not occur. Occasionally, bone overlaps may project lines on the images of tooth roots on periapical radiographs and simulate the presence of a root fracture (false positive for fracture) (Figure 1). Cone beam computed tomography image has significantly greater sensitivity in diagnosing root fracture compared to periapical radiography $(1,3,5,6,34)$. The most indicated exam for the evaluation of root fractures is the CBCT scans $(2,10)$ with small volume $(16)$ and high resolution. However, this examination must be obtained by a professional with adequate training for this subtype of diagnosis.
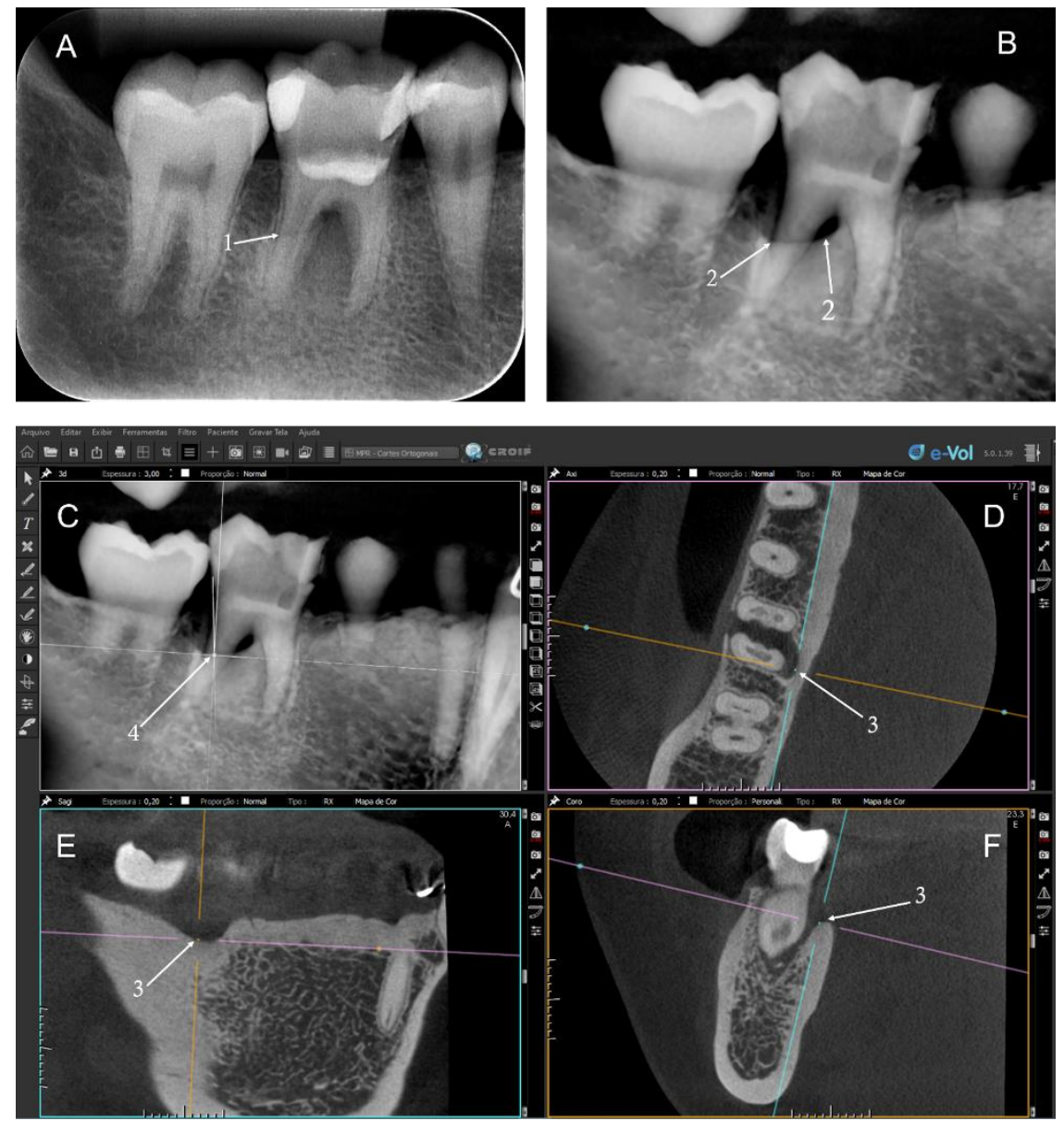

Figure 1. Radiolucent line (1) at the distal root of tooth \#46 on periapical radiography (PR) (A). Presence of other lines in the roots on PR. Patient with local pain symptoms. CBCT scans was performed due to suspicion of root fracture. The line on the periapical image was not a fracture, but a projection of the lingual alveolar ridge $(2,3$ and 4$)$, visible in a 3D tomographic section $(5 \mathrm{~mm})(B$ and $C)$. Multiplanar sections $(D, E, F)$ indicated the alveolar ridge projected in the synchronized $3 \mathrm{D}$ section (C) (4) forming the image of a line (2).

\section{Classifications of Root fractures}

The reference classification of this study based on aspects of CBCT images includes:

1. Orientation of the fracture line - It can be distributed in 1 - horizontal root fracture; 2 vertical root fracture; 3 - oblique root fracture. It sounds simple, but doubts are frequent with this classification. Rarely (if ever) true vertical and horizontal fractures will be encountered, therefore, moderate slopes with these designations should be accepted. Oblique fractures are diagonal, oriented between horizontal and vertical. Fracture line angle can be used as a synonym for fracture line orientation (Figure 2). 
2. Root position of the fracture - it can be distributed in: 1 - fracture in the cervical third; 2 - fracture in the middle third; 3 - fracture in the apical third. Fractures may overlap between the root thirds, and when describing this aspect should be considered (i.e., root fracture extending from the cervical third to the middle third) (Figure 2).

3. Fracture's coronal-radicular position - it can be distributed in: 1 - coronary fracture; 2 coronal-radicular fracture; 3 - root fracture. Here it can also be included whether or not there is pulp involvement by the fracture line (Figure 2).

4. Continuity of the fracture - it can be distributed in: 1 - crack; 2 - incomplete fracture; 3 complete fracture. Crack is an incomplete fracture with very small dimensions, which can occur in the crown, crown with radicular extension or just radicular, being invariably difficult to visualize. There is no consensus in the literature on the precise distinction between a crack and a dental fracture. Incomplete fracture is a well-defined line on one edge with absent extension on another edge, and it may be true incomplete or incomplete only on visualization (Figure 2).

5. Bone extension of the fracture, it can be distributed in: 1 - supraosseous fracture, 2 fracture at the bone level; 3 - infraosseous fracture. It is important to describe the fracture extension in relation to the bone level (if it is visible), as it can impact the prognosis. There are other classifications such as according to the type of trauma, presence or absence of intrarradicular post, etc. The description in the radiographic report must take into account these classifications, often combining them, for a better characterization (Figure 2).

\section{Fracture orientation}

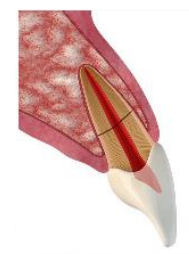

1- Horizontal

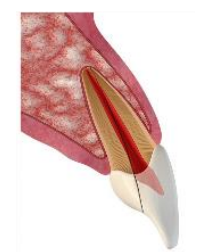

2- Vertical

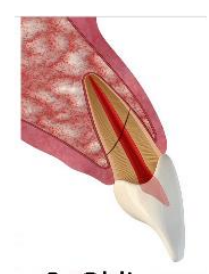

3- Oblique
2. Root position

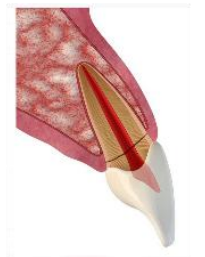

1- Coronal

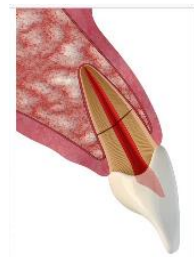

2- Middle

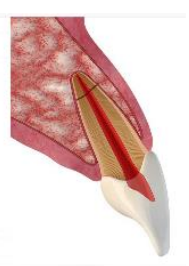

3- Apical

\section{Coronoradicular position}

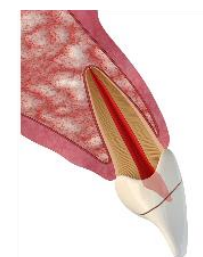

1- Coronal

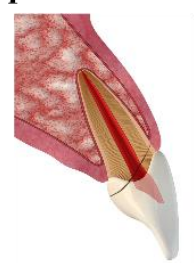

2- Coronoradicular

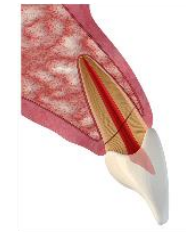

3- Radicular
4. Continuity of the Fracture

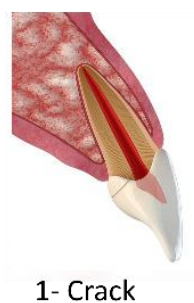

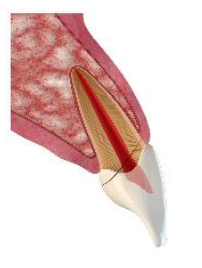

3- Complete

5. Bone Location
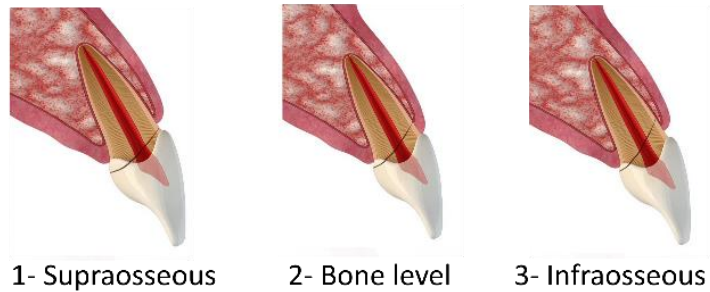

Figure 2. Distribution of root fractures. 1 (A) Fracture line orientation: 1. horizontal; 2. vertical; 3. oblique. 2 (B) Root position of the fracture: 1 . cervical third; 2 . middle third; 3 . apical third; 3 (C) Coronoradicular fracture position: 1. coronary fracture; 2 . coronal-radicular fracture; 3 . root fracture; 4 (C) Fracture continuity: 1. crack; 2. incomplete fracture; 3. complete fracture; 5 (C) Bone extension of the fracture: 1. supraosseous fracture, 2. fracture at the bone level; 3. infraosseous fracture. 


\section{Sensitivity and specificity in root fracture}

The methodologies for evaluating root fractures are heterogeneous $(17,26)$, which implies a careful and critical interpretation of the results. Sensitivity and specificity tests are frequently used in studies. Understanding these tests for tomographic analysis of root fractures becomes important:

1. Sensitivity test: constitutes the proportion of fractured teeth (real tooth) that show positive results for fracture on the $\mathrm{CBCT}$ image;

2. Specificity test: constitutes the proportion of intact teeth (real tooth) that have a negative result for fracture on CBCT images. In CBCT images diagnosis of root fracture, the result with high sensitivity is the increased ability to find existing fractures. High specificity is the ability to little err on the side with false positives for fracture.

In CBCT images diagnosis of root fracture, the result with high sensitivity is the increased ability to find existing fractures. High specificity is the ability to err on the side with false positives for fracture.

The presence of artifacts may be responsible for the reduction in the specificity of the tomographic exam (9). The ideal is the joint result of high sensitivity and high specificity, which can be unified in high accuracy. The accuracy in CBCT images is significantly higher for the detection of root fractures that have a thickness greater than $150 \mu \mathrm{m}$, but can be visible from $50 \mu \mathrm{m}$ (interesting that the minimum voxel of the tested equipment is even a little lower) $(12,18)$. Root fracture detection with high spatial resolution CBCT can reach $80 \%$ to $90 \%$ of cases $(4,5)$, and with the presence of artifacts, these numbers are generally smaller. CBCT scans allowed greater precision in the detection of root fractures $(1,4,6,9,34)$ compared to periapical radiographs. Special care must be taken even with the use of CBCT scans during the diagnosis of incomplete root fractures of very small dimensions that may go unnoticed (34).

Root fractures caused by dental occlusion, chewing and clenching are generally more difficult to be diagnosed than fractures caused by dentomaxillofacial trauma (accidents), and the latter must undergo special care in the evaluation of the alveolar ridge (33).

\section{CBCT Image Quality}

In the evaluation of tooth fractures, the use of CBCT scans of small volume and high resolution (smaller voxel size) is indicated. In addition to voxel size, many other factors interfere with image clarity, such as noise rate, contrast resolution, image dynamic range, presence of artifacts, equipment calibration, patient stability, among others. Likewise, the final result of all factors must be the so-called "spatial resolution", which is translated as the final sharpness of the image. Tiny details are of great importance in the evaluation of root fractures, leading to the need for magnifications in the visualization of tomographic images. For image enlargements maintaining diagnostic quality, high spatial resolution CT scans are necessary (34).

For the diagnosis of root fractures, some configuration parameters of the tomographic apparatus are important. The higher kilovoltage $(\mathrm{kV})$ allows for greater penetration of $\mathrm{x}$-rays, often leading to reduced artifacts, and facilitating the diagnosis of fractures. The higher milliamperage $(\mathrm{mA})$, as well as a greater number of base images (8) also enables the reduction of artifacts, as well as the reduction of noise, mainly increasing the specificity of the exam $(19,20,21)$ (reducing false positives for root fracture). Image preparation with adjustments for brightness, contrast, noise reduction, sharpen (14) are important and interdependent, and should be understood as a malleable set, which can be adjusted to fulfill specific functions. The use of advanced software designed to work in a refined way in the adjustments of tomographic images, as well as good navigation tools, favors the process of diagnosing root fractures.

\section{Radiologist Professional Training}

The high spatial resolution CT scanners are important for diagnosing root fractures, but diagnosis is the end product of image interpretation. Large root fractures are easy to interpret. Minor root fractures, especially when associated with noise and especially artifacts, may lead to challenging diagnoses, and the specific training of the radiologist/endodontist for this type of diagnosis is essential. Next, the main patterns for fracture diagnosis will be discussed.

\section{Fracture line patterns in anterior teeth}

The anterior teeth, especially the maxillary incisors, are the most exposed to traumatic dental injury. Likewise, teeth with intracanal posts and prosthetic crowns are more susceptible (32). The preparation of a more extensive root canal for the installation of a post makes it possible to reduce the 
structure and tooth fragility. It should be noted that the intracanal post does not protect the tooth from root fracture. The root fractures most often do not occur at the apex of posts. The mastication leads to a greater concentration of forces in the cervical third of the root, with an oblique vector, mainly through the buccal sense (38-40). For this reason, fractures of maxillary anterior teeth occur mainly obliquely through the buccal route of the coronal root third, but any other fracture height and orientation (angle) is possible, but less frequently. Posterior teeth have more diversified angles, tending to be more vertically oriented (27).

Factors associated with the root fracture line

The root fracture lines are generally not completely straight and uniform (11), its present specific locations and shapes that are unlikely for artifacts, although they should always be carefully analyzed through dynamic navigation in all planes of the multiplanar reconstruction (MPR).

Forms of lines suggestive of root fractures:

- Line with a curved shape: a line with a curved shape (Figure 3 and 5) on axial CBCT slices is highly suggestive of fracture. The same is not true for other slices. The artifacts may be curved (Figure 4) on sagittal, coronal, and oblique views, but are not curved on axial views.
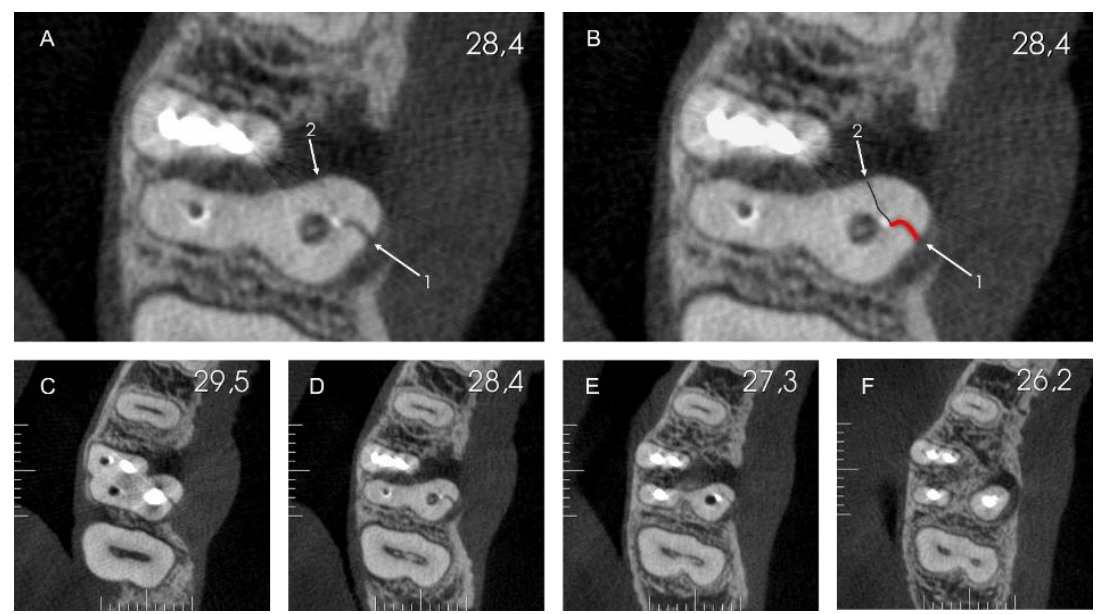

Figure 3. CBCT scans in axial plane with root fracture line (A - F). Curved line (1) and well defined in axial sections is indicative of fracture, schematically represented in red (B). Thin and discrete line (2) in continuity schematically represented in black (B). Bone loss in local vertical alveolar. Location: palatal root of maxillary molar.

- Irregular line: an irregular line (Figure 5) is suggestive of root fracture. The more irregular, the more suggestive. Artifacts are straight or minimally irregulars.

Positions of lines suggestive of root fractures:

- Line in a location with no possibility of artifact projection (Figure 5): significant continuous line above or below (in axial sections) of dense area with potential for artifact formation is highly suggestive of fracture.

- Line with continuity in navigation: line with continuity in several sequential slices of navigation in a place without artifacts. Noise can form small, discreet lines, including curved lines in axial slices as well as other slices. The major difference is that the noise is not continuous when navigating in several sequential slices, and when navigating in 3 or 4 slices, the noise disappears. It can form other noises, more in other positions, without continuity. The fracture line must appear in at least 4 (preferably more) sequential slices, otherwise it could be noise. 


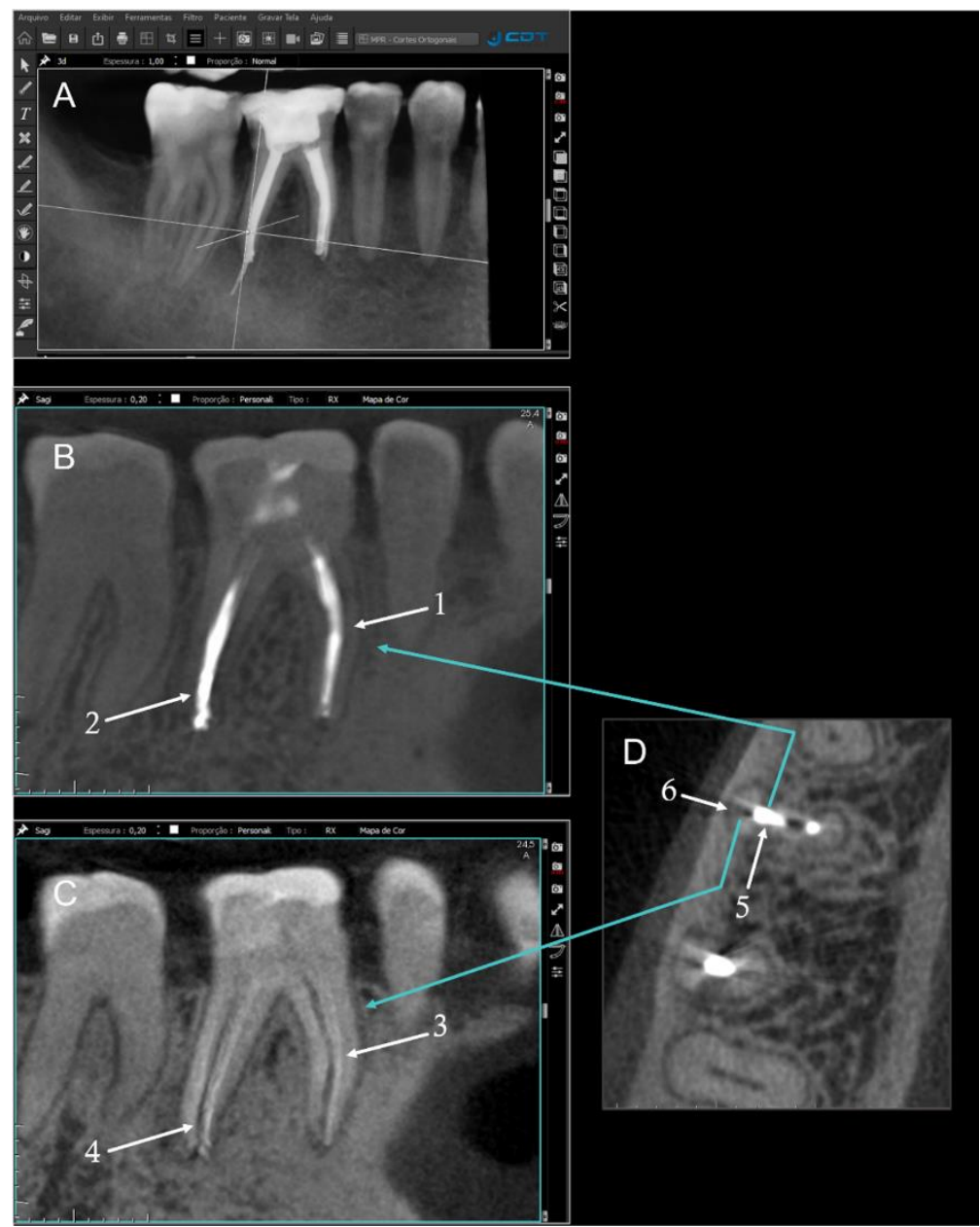

Figure 4. Presence of dense endodontic filling material (5), artifact-generating font (6) visible in the CBCT scans of the MPR (B, C and D). Curved shape of the endodontic material (1) forms in the neighborhood a dark artifact also with a curved shape (3), like a copy. Discreetly curved shape of the endodontic material (4) forms in the neighborhood a dark artifact also with a curved shape (3), which may be a fine, sharp line of artifact. 3D referential indexed (A).
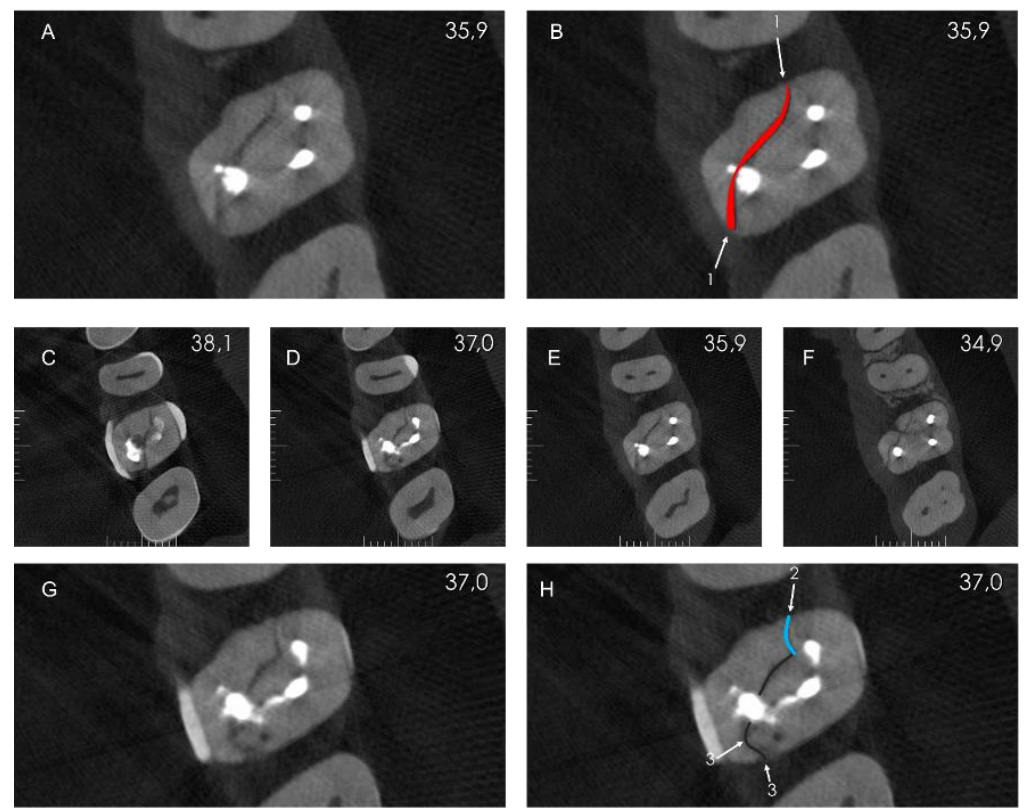

Figure 5. CBCT scans in axial planes with irregular root fracture line $(A$ to $H)$. Axial tomographic section (B) with irregular line (1) indicative of fracture schematically represented in red. Line present in other tomographic sections of MPR. Line in place without the possibility of projecting artifacts $(\mathrm{H})$ schematically represented in blue. Curved line (3) in axial section indicative of fracture schematically represented in black $(\mathrm{H})$. Location: maxillary molar root. 
Suggestive associations of root fracture lines:

- Association of the presence of material in a location of the line in the image: material, mainly from endodontic fillings, may penetrate and be visible in the fracture line, discarding the hypothesis that the line is just an artifact.

- Association of presence of bone resorption in a line site on the image: bone resorption in a line site on the image may lead to a suggestion of fracture, although it may coincide with periodontal disease.

\section{Bone resorption $\mathrm{x}$ root fracture line}

The bone resorption in a site of the possible root fracture is an important sign, but it should not be evaluated in isolated form. The reason for bone resorption is associated with bacterial infiltration and proliferation in the fracture line, via periodontal or via canal, leading to the development of an inflammatory process from the infectious process. Bone resorption does not occur immediately after the fracture, and a certain time is necessary for the proliferation of bacteria in the fracture line, and development of the inflammatory process and, subsequently, bone resorption. A study in dogs (14) indicates that the onset of detection of bone resorption at an infection site on CBCT images occurs in $33 \%$ of cases on day 14 after aggression, and 83\% of cases on day 21 after aggression. However, it should be considered that this study was carried out in dogs, whose metabolic process differs from that of humans. Bone metabolism in humans is different than in dogs, therefore, a different time must be waited to start the resorption process visible in CBCT images. In diabetic patients, immunocompromised patients or in cases of infections with more aggressive micro-organisms, this time may be shorter.

Bone resorption from origin of root fracture aggression (Figure 6 ) is generally more localized and associated with the shape of the fracture line, being more elongated with vertical fractures (13). The fracture line is the epicenter of aggression often leading to bone resorption relatively equidistant from this line. The lateral angles of bone resorption resulting from fractures are usually closer to the straight than the angles of periodontal diseases, which are more open, and this fact becomes more evident in vertical fractures in posterior teeth $(24,25)$. The visibility of bone resorption on CBCT scan is useful for diagnosis, even when it is not possible to visualize the fracture line (29). The documentation of signs and symptoms associated with time is important in the anamnesis for the interpretation of the CBCT exam. The patients with root fractures can usually present clinical signs and symptoms, such as provoked pain, pain on percussion, occlusal pain and even the presence of periodontal abscess $(13,23)$.

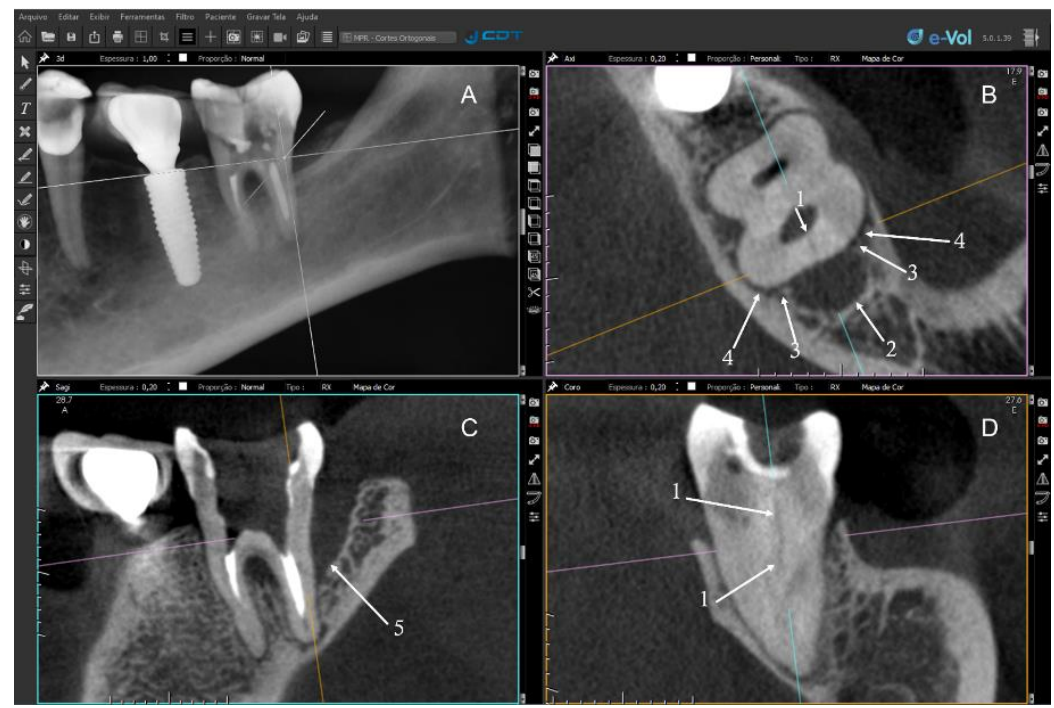

Figure 6. Discrete fracture line (1) incompletely visible on the CBCT slices of the MPR (B and D). Bone loss (2) located equidistant from the fracture line. Lateral angles of bone loss close to the rectum (3) and preserved adjacent periodontal space (4) visible (B). Wedge aspect of bone loss (5) suggests incomplete fracture visible (C), but this shape is also common in periodontal disease. 3D referential indexed (A).

Differential diagnosis of root fracture line

Artifacts $x$ fracture line

Dark artifacts: dark artifacts are the most harmful for diagnosis. It is important to evaluate the artifact's generating source and the artifact itself, from beginning to end. The artifact may originate 
from a neighboring or even distant tooth (Figure 7). The artifact may (or may not) extend outside the root, which evidently does not occur with root fracture. If possible and feasible, early removal of intracanal endodontic material is indicated to reduce CBCT artifacts (28).
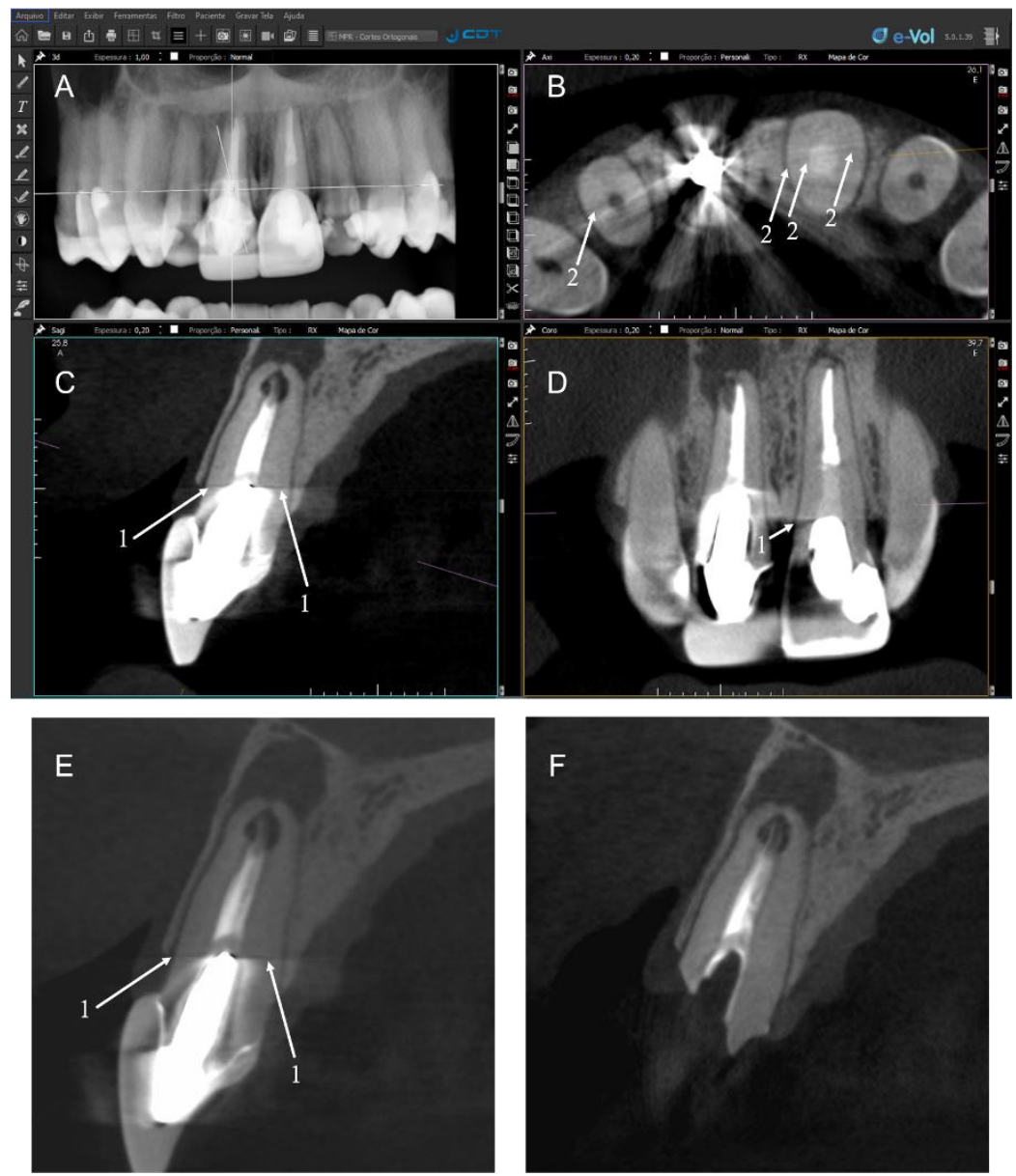

Figure 7. CBCT scans in MPR with conventional contrast (B, $C$ and D). Slices with reduced contrast (E). 3D indexed referential (A). Artifact (1) forming a dark line at the apex of the intracanal post, which could be confused with a fracture ( $C$ and $E$ ). The visualization of post apex limit is best evidenced with the preset of contrast reduction using BAR filter on the e-Vol DX (E). New tomography slice after post removal (F) showing the elimination of the artifact line. Images of artifact lines (2) can be projected onto teeth adjacent to the generating source (B).

Dark artifact at post apex: there is a specific type of dark artifact that occurs in the form of a line at post apex (30) (Figure 7) due to the high difference in local density, presenting the following characteristics: straight line or with an angle close to horizontal (inclination less than 20 degrees), which may or may not pass outside the root. As this line is often well defined, formed by an image of the root, at the apex of a retainer, it can lead to a mistaken diagnosis of root fracture. It is important to remember that: 1 - fracture at the post apex is uncommon; 2 - fracture with a near-horizontal orientation at the post apex is highly uncommon; 3 - fracture without local bone loss is highly uncommon.

Light artifact: the light artifacts (blooming artifact) are projected in the vicinity of areas or bodies of high density $(31,36)$. It is an artifact of light gray expansion that is turned into white, disturbing the regional visualization. The reduction of contrast of the image attenuates this artifact. The blooming artifact reduction filter (BAR) of the e-Vol DX software $(34,36)$ (Figure 7 and 8 ) is a preset that that explore in a logarithmic way the reduction of the contrast, using the maximum dynamic range of the DICOM, helping the evaluation of neighboring areas of dense artifact-forming materials. It is important that the scan DICOM file has a high dynamic range originally for good results. Many CT scanners produce DICOM files with low dynamic range leading to high limitation or impossibility of reducing artifacts. This aspect is important prior to acquiring a tomograph. 

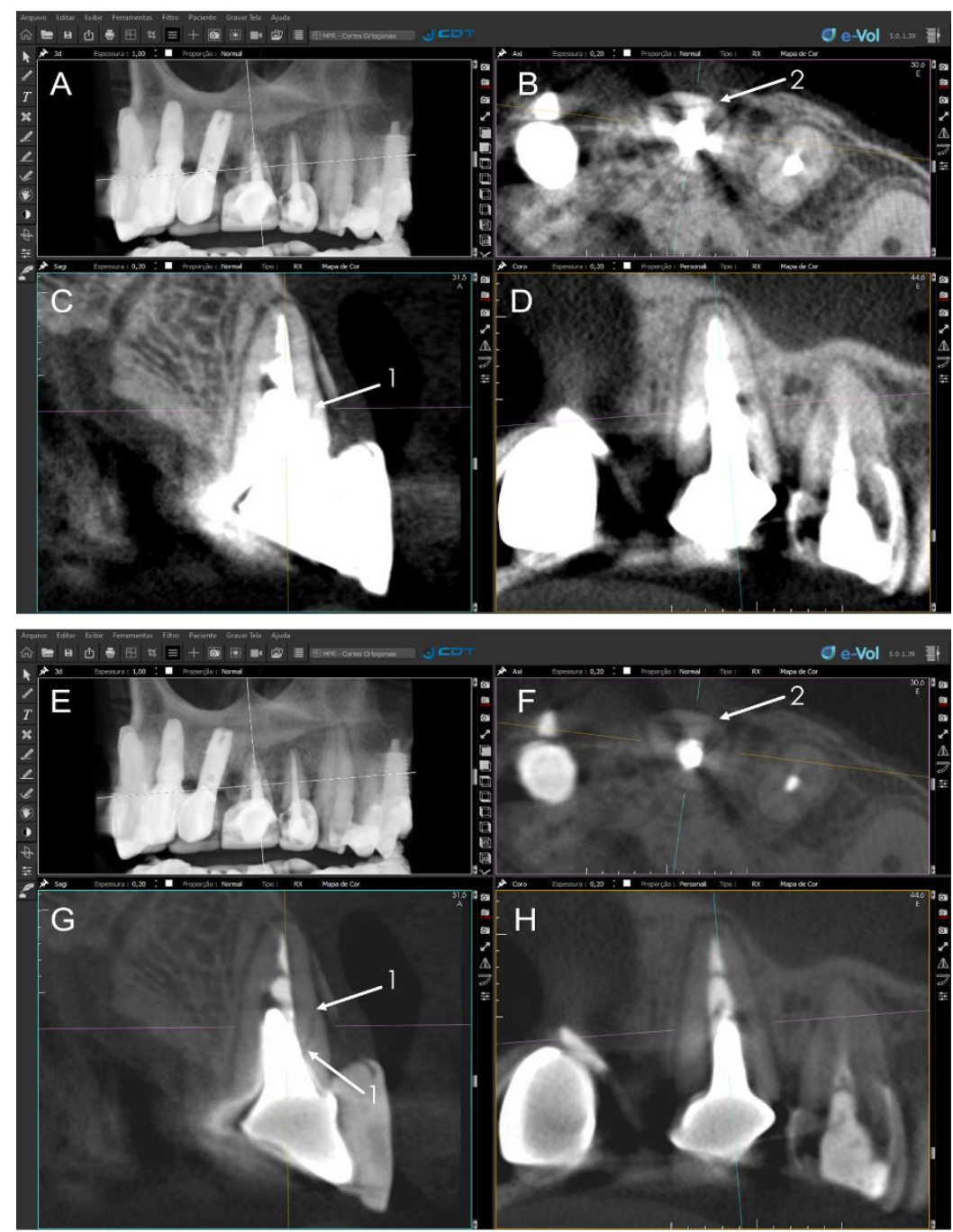

Figure 8. CBCT scans (MPR) with conventional contrast ( $B, C$ and $D)$. Image with application of contrast reduction preset with BAR filter on e-Vol DX ( $F, G$ and $H)$. $3 \mathrm{D}$ indexed referential ( $A$ and $E$ ). Fracture line (1) partially visible in the sagittal slice with conventional contrast $(C)$ and with wider visibility in the sagittal slice with reduced contrast $(G)$. The curved shape of the line (2) in the axial plane (A and F) is indicative of root fracture. Line distant from the area of possible artifact generation is indicative of root fracture, which can lead to doubt in the axial plane with conventional contrast (B), and with contrast reduction (F) the fracture line (2) is clearly far from the post (artifact-generating source).

\section{Accessory canal $x$ root fracture line}

Accessory root canals such as the lateral canal, secondary canal, intercanal, cavus canal, among others, may have sufficient caliber to be visible in the high spatial resolution CBCT image (38). Accessory canals can be confused with fractures by professionals without specific training for this type of diagnosis. This confusion should not exist as there is a direct way of distinguishing between accessory canal and fracture line. The evaluation must follow the following steps: when finding a hypodense line in a tomographic slice, the MPR navigation lines must be adjusted so that they are parallel and perpendicular to the hypodense line (parallax correction) (35), and after carefully adjusted the accessory canal image will invariably appear as one line on an MPR CBCT slice, another line on another slice, and a dot on the third slice. The 3 sections of the MPR then present images with the sequence: line-line-dot (Figure 9). In case of fracture, the following sequence will appear: line-line-area moderately hypodense and with a nonspecific (amorphous) shape (Figure 9). 


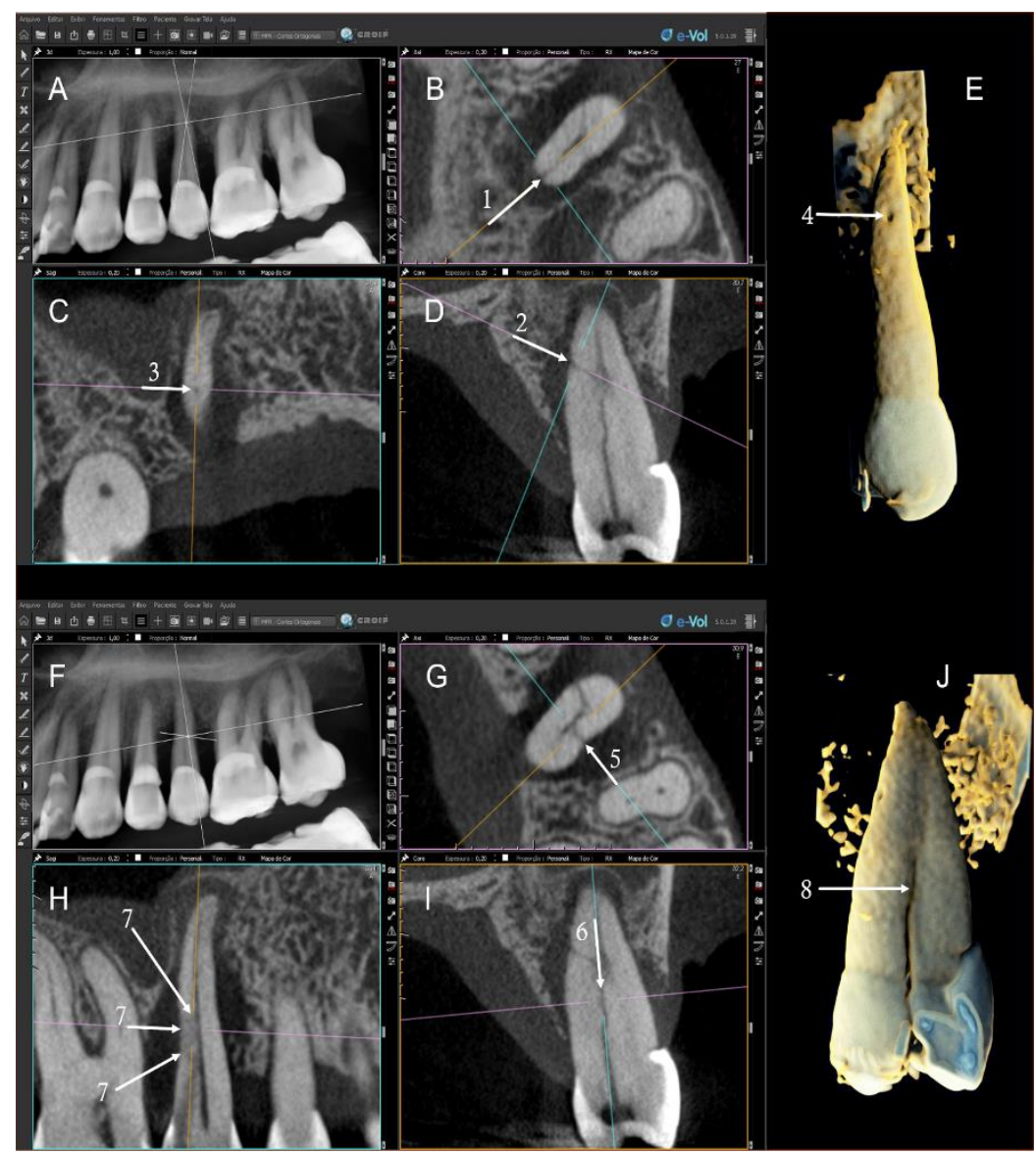

Figure 9. Accessory root canal visible in MPR CBCT sections (B, $C$ and $D)$ in the form of a line (1) in the section (B); in line shape (2) in slice (D) and in point shape (3) in

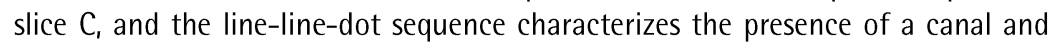
excludes fracture. Image of lateral canal (4) also visible in realistic 3D (E). Visible fracture in tomographic sections of the MPR ( $G$ and $I)$ in the form of a line (5) in the section $(G)$; line-shaped (6) in slice (I) and amorphous, moderately hypodense area (7) in slice (H). Image of fracture (4) also visible in realistic 3D (J). 3D referential indexed ( $A$ and $F$ ).

\section{Radicular groove}

Anatomical radicular groove (Figure 10) is a frequent variation, especially in mandibular premolars, but it can occur in other teeth. The groove may appear as a vertical line along the long axis of the root, and it may eventually be very narrow and similar to a fracture line. It may also have local bone loss. The most important feature of the anatomical root groove is that its edges are rounded, which differs from the fracture line that does not have this property. 

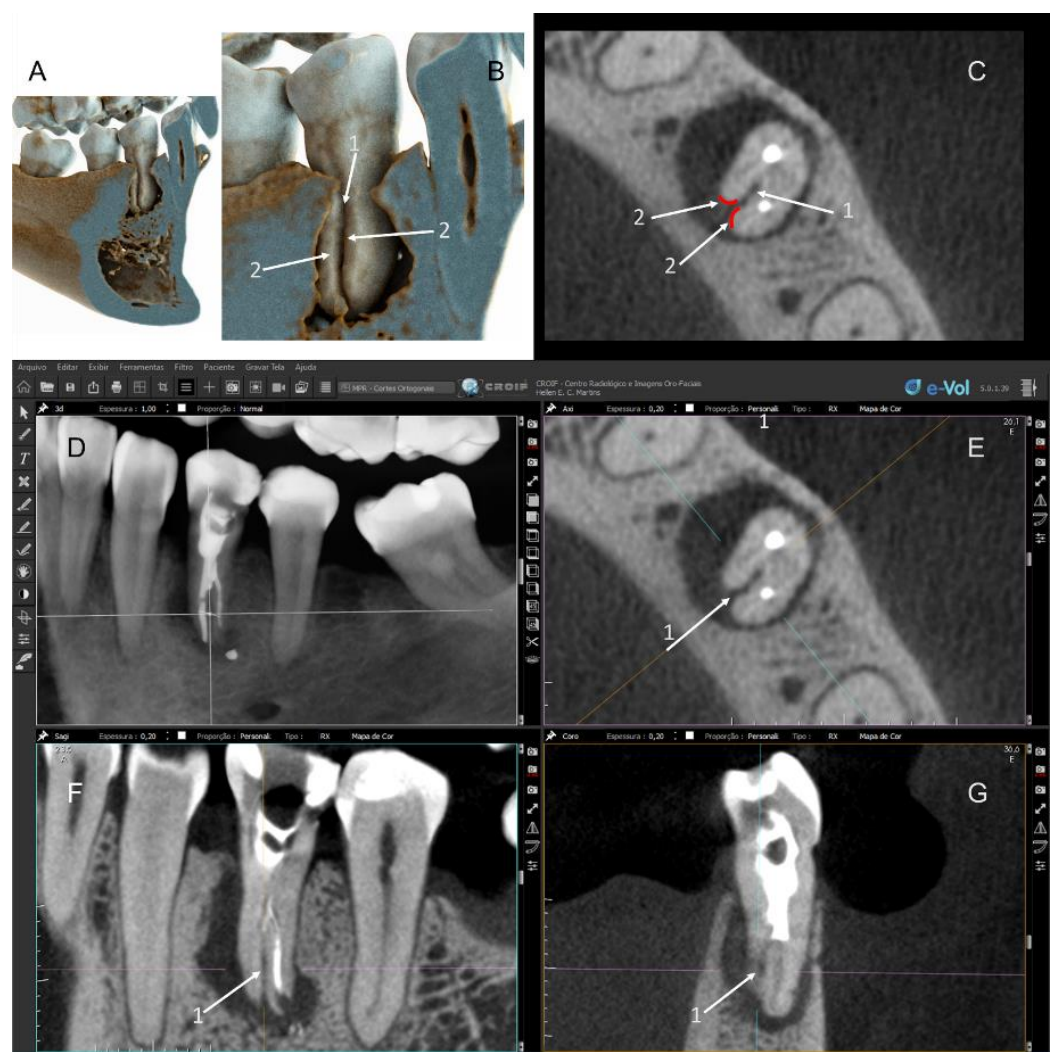

Figure 10. Radicular groove (1) visible on tomographic scans (MPR)(C, E, F and G) in the form of a fracture-like line. The rounded margins schematically represented in red (2) characterize the radicular groove and differ from fractures, being visible in the axial section (B) and in realistic 3D (A and B). 3D referential indexed in (D).

\section{Final considerations}

Root fractures are unpleasant accidents that may be responsible for tooth loss. The highest prevalence of traumatic dental injury occurs in the maxillary anterior teeth, which may be involved with this type of trauma. However, any tooth can experience a root fracture, treated or not endodontically, with or without an intraradicular post. The risk factors point to teeth that have less root structure support and presence of post, which often present substantial differences in hardness compared to dentin, which favors a higher frequency of root fracture. Imaging examination is essential for the diagnosis of root fractures, and the smaller its size, the greater the challenge. Extensive fractures are easier to diagnose, which in most cases does not justify comparative experiments, as they are evident even in limited radiographic examinations. Fracture lines and root fractures that may be associated with phantom conditions that mimic fractures should be carefully analyzed.

Various manufacturers have developed CBCT devices, each one associated by its specific software. The need for high quality images, visualization of complex anatomical structures, precise identification of occult lesions and root fracture line, associated with the reduction of artifacts stimulated the development of the e-Vol DX software. This CBCT software present the ability to import, work with DICOM files, and standardize image adjustments to analyze CBCT volumes from different sources. Another feature has been a response to the unmet need for software that preserved all the dynamic range of DICOM files, as it analyzes DICOM files from different CT scanners and produces images with normal contrast. Its filters have been developed to reduce artifacts and show the shades of gray that best characterize the actual structure of the object on the image (34).

CBCT is the exam indicated to identify a root fracture. It is also added to the success of the diagnosis that the professional has scientific knowledge, training and mastery of advanced CBCT software. 
Acknowledgements

Supported in part by grants from the National Council for Scientific and Technological Development (CNPq grants 306682/2017-6 to C.E.). The first and last author participated in the development of this software.

\section{Resumo}

0 objetivo desta revisão crítica da literatura é discutir os fatores clínicos relevantes associados às fraturas radiculares FR visualizados por meio de um novo software de CBCT. As fraturas radiculares constituem uma ocorrência comum e um desafio na prática clínica, em que o diagnóstico torna-se essencial para a definição de uma tomada de decisão rápida e precisa. A caracterização da FR pode envolver diversos aspectos, como orientação da linha de fratura (horizontal, vertical, oblíqua), posição radicular da fratura (cervical, médio, apical), posição coronoradicular da fratura (coronária, coronorradicular, radicular), continuidade da fratura (trinca, fratura incompleta, completa), extensão óssea da fratura (supraóssea, nivel ósseo, fratura infraóssea). Os exames de imagens têm sido usados rotineiramente para auxiliar no diagnóstico de RF. Mesmo com a tomografia computadorizada de feixe cônico (TCFC) de alta resolução, muitas vezes permanecem muitas dúvidas sobre o resultado do diagnóstico. São identificadas muitas interferências na análise da qualidade da imagem para determinar o diagnóstico, como a nitidez, o ruído, artefatos claros e escuros, dentre outros. 0 conhecimento do profissional é fundamental para identificar os diferentes padrões de linhas de fraturas e suas repercussões nos tecidos ósseos adjacentes, bem como para a análise de artefatos que podem ocultar ou apresentar semelhanças com as linhas de fraturas. As linhas de fraturas e fraturas radiculares que podem estar associadas às condições fantasmas que mimetizam fraturas devem ser analisadas cuidadosamente. $A$ TCFC constitui o exame por imagem indicado para identificar uma fratura radicular. Acrescenta-se ao sucesso do diagnóstico o fato do profissional apresentar conhecimento científico, treinamento e domínio de softwares avançados de TCFC. 


\section{References}

1. Hassan B. Metska ME, Ozok AR, van der Stelt P, Wesselink PR. Detection of vertical root fractures in endodontically treated teeth by a cone beam computed tomography scan. J Endod 2009;35:719-722.

2. Melo SLS, Bortoluzzi EA, Abreu M, Corrêa LR, Corrêa M. Diagnostic ability of a cone-beam computed tomography scan to assess longitudinal root fractures in prosthetically treated teeth. J Endod 2010;36:1879-1882.

3. Yiit-Özer S. Detection of vertical root fractures of different thicknesses in endodontically enlarged teeth by cone beam computed tomography versus digital radiography. J Endod 2010;36:1245-1249.

4. Edlund M, Nair MK, Nair UP. Detection of vertical root fractures by using cone-beam computed tomography: A clinical study. J Endod 2011;37:768-772.

5. Wang $P$, Yan XB, Lui DG, et al. Detection of dental root fractures by using cone-beam computed tomography. Dentomaxillofac Radiol 2011;40:290-298.

6. Metska ME, Aartman IHA, Wesselink PR, Özok AR. Detection of vertical root fractures in vivo in endodontically treated teeth by cone-beam computed tomography scans. J Endod 2012;38:1344-1347.

7. Kajan ZD, Taromsari M. Value of cone beam CT in detection of dental root fractures. Dentomaxillofac Radiol 2012;41:3-10.

8. Bechara B, McMahan CA, Nasseh I, Geha H, Hayek E, Khawam G, Raad M, Noujeim M. Number of basis images effect on detection of root fractures in endodontically treated teeth using a cone beam computed tomography machine: an in vitro study. Oral Surg Oral Med Oral Pathol Oral Radiol 2013;115:676-681.

9. Patel $\mathrm{S}$, Brady $\mathrm{E}$, Wilson R, Brown J, Mannocci F. The detection of vertical root fractures in root filled teeth with periapical radiographs and CBCT scans. Int Endod J 2013;46:1140-1152.

10. Bechara B, McMahan CA, Noujeim M, Faddoul T, Moore WS, Teixeira FB, Geha H. Comparison of cone beam CT scans with enhanced photostimulated phosphor plate images in the detection of root fracture of endodontically treated teeth. Dentomaxillofacl Radiol 2013;42:20120404.

11. Huang $C C$, Chang YC, Chuang MC, Lin HJ, Tsai YL, Chang SH, Chen JC, Jeng JH. Analysis of the width of vertical root fracture in endodontically treated teeth by 2 micro-computed tomography systems., J Endod 2014;40, 698-702.

12. Brady $E_{1}$ Mannocci $F$, Brown J, Wilson R, Patel S. A comparison of cone beam computed tomography and periapical radiography for the detection of vertical root fractures in nonendodontically treated teeth. Int Endod J 2014;47:735-746.

13. Komatsu $K$, Abe $Y$, Yoshioka $T$, Ishimura $H$, Ebihara $A$, Suda $H$. Differential diagnosis of vertical root fractures using reconstructed three-dimensional models of bone defects. Dentomaxillofac Radiol 2014;43: 20140256.

14. Nascimento MC, Nejaim Y, de Almeida SM, Bóscolo FN, Haiter-Neto F, Sobrinho LC, Silva EJ. Influence of cone beam CT enhancement filters on diagnosis ability of longitudinal root fractures. Dentomaxillofac Radiol 2014;43:3-7.

15. Kuusisto N, Vallittu PK, Lassila LV, Huumonen S. Evaluation of intensity of artefacts in CBCT by radio-opacity of composite simulation models of implants in vitro. Dentomaxillofac Radiol 2015;44:20140157.

16. likubo $M$, Nishioka $T$, Okura $S$, Kobayashi $K$, et al. Influence of voxel size and scan field of view on fracture-like artifacts from gutta-percha obturated endodontically treated teeth on cone-beam computed tomography images. Oral Surg Oral Med Oral Pathol Oral Radiol Endod 2016;122:631-637.

17. Talwar S, Utneja S, Nawal RR, Kaushik A, Srivastava D, Oberoy SS. Role of Cone-beam Computed Tomography in Diagnosis of Vertical Root Fractures: A Systematic Review and Meta-analysis. J Endod 2016;42:12-24.

18. Makeeva IM, Byakova SF, Novozhilova NE, Adzhieva EK, Golubeva GI, Grachev VI, Kasatkina IV. Detection of artificially induced vertical root fractures of different widths by cone beam computed tomography in vitro and in vivo. Int Endod J 2016;49:980-989.

19. Wanderley VA, Neves FS, Nascimento MCC, Monteiro GQM, Lobo NS, Oliveira ML, Nascimento Neto JBS, Araujo LF. Detection of incomplete root fractures in endodontically treated teeth using different high-resolution cone-beam computed tomographic imaging protocols. J Endod 2017;43:1-5.

20. Gaêta-Araujo H, Souza GOS, Freitas DQ, Oliveira-Santos C. Optimization of tube current in conebeam computed tomography for the detection of vertical root fractures with different intracanal materials. J Endod 2017;43:1-6. 
21. Tangari-Meira R, Vancetto JR, Dovigo LN, Tosoni GM. Influence of tube current settings on diagnostic detection of root fractures using cone-beam computed tomography: an in vitro study. J Endod 2017;43:1701-1705.

22. Dutra KL, Pachêco-Pereira $C$, Bortoluzzi EA, Flores-Mir $C$, Lagravère $M O$, Corrêa $M$. Influence of intracanal materials in vertical root fracture pathway detection with cone-beam computed tomography. J Endod 2017;43:1522-1527.

23. Kobayashi-Velasco S, Salineiro FCS, Gialain IO, Cavalcanti MGP. Diagnosis of alveolar and root fractures: an in vitro study comparing CBCT imaging with periapical radiographs. J App Oral Sci 2017; 25:227-233.

24. Fayad MI, Ashkenaz PJ, Johnson BR. Different representations of vertical root fractures detected by cone-beam volumetric tomography: a case series report. J Endod 2012;10:1435-42.

25. Ee J, Fayad MI, Johnson BR. Comparison of endodontic diagnosis and treatment planning decisions using cone-beam volumetric tomography versus periapical radiography. J Endod 2014;40:9106.

26. Salineiro FCS, Kobayashi-Velasco S, Braga MM, Cavalcanti MGP. Radiographic diagnosis of root fractures: a systematic review, meta-analyses and sources of heterogeneity. Dentomaxillofac Radiol 2017;46:20170400.

27. Mizuhashi F, Ogura I, Sugawara $Y$, Oohashi M, Mizuhashi $R$, Saegusa H. Diagnosis of root fractures using cone-beam computed tomography: difference of vertical and horizontal root fracture. Oral Radiol 2020.

28. Hekmatian E, Karbasi M, Fathollahzade $H$, Sheikhi M. Detection of vertical root fractures using cone-beam computed tomography in the presence and absence of gutta-percha. Scientific World J 2018;1920946.

29. Byakova SF, Novozhilova NE, Makeeva IM, Grachev VI, Kasatkina IV. The accuracy of CBCT for the detection and diagnosis of vertical root fractures in vivo. Int Endod J 2019;52:1255-1263.

30. Bueno MR, Estrela C, Figueiredo JAP, Azevedo B C. Map-reading strategy to diagnose root perforations near metallic intracanal posts by using cone beam computed tomography. J Endod 2011;37;85-90.

31. Decurcio DA, Bueno MR, Alencar AHG, Porto OCL, Azevedo BC, Estrela C. Effect of root canal filling materials on dimensions of cone-beam computed tomography images. J Appl Oral Sci 2012;20:260-267.

32. Estrela C, Bueno MR, Porto OCL, Rorigues CD, Pécora JD. Influence of intracanal post on apical periodontitis identified by cone-beam computed tomography. Braz Dent J 2009;20:370-375.

33. Soares PBF, Vilela ABF, Moura CCG, Estrela C, Bueno MR, Soares CJ. Lateral luxation of incisor a case report of using a new cone-beam computed tomography software and reposition guideline. Braz Dent J 2020;31:337-343.

34. Bueno MR, Estrela C, Azevedo BC, Diogenes A. Development of a new cone-beam computed tomography software for endodontic diagnosis. Braz Dent J 2018;29:517-529.

35. Estrela C, Couto GS, Bueno MR, et al. Apical foramen position in relation to proximal root surfaces of human permanent teeth determined by using a new cone-beam computed tomographic software. J Endod 2018;44:1741-1748.

36. Estrela C, Costa MVC, Bueno MR, Rabelo LEG, Decurcio DA, Silva JA, Estrela CRA. Potential of a new cone-beam CT software for blooming artifact reduction. Braz Dent J 2020;31:582-588.

37. Gregoris Rabelo LE, Bueno MDR, Costa MVCD, de Musis CR, Estrela CRA, Guedes OA, Gavini G, Estrela C. Blooming artifact reduction using different cone-beam computed tomography software to analyze endodontically treated teeth with intracanal posts. Comput Biol Med 2021;136:104679.

38. Xu T, Tay FR, Gutmann JL, Fan B, Fan W, Huang Z, Sun Q. Micro-computed tomography assessment of apical accessory canal morphologies. J Endod 2016;42:798-802.

39. Lazari PC, de Carvalho MA, Del Bel Cury AA, Magne P. Survival of extensively damaged endodontically treated incisors restored with different types of posts-and-core foundation restoration material. J Prosthet Dent 2018;119:769-776.

40. Carvalho MA, Lazari PC, Gresnigt M, Del Bel Cury AA, Magne P. Current options concerning the endodontically-treated teeth restoration with the adhesive approach. Braz Oral Res 2018;32(suppl 1):e74.

41. Magne P, Lazari PC, Carvalho MA, Johnson T, Del Bel Cury AA. Ferrule-Effect Dominates Over Use of a Fiber Post When Restoring Endodontically Treated Incisors: An In Vitro Study. Oper Dent 2017;42:396-406. 
42. Garcia de Paula-Silva FW, Hassan B, Bezerra da Silva LA, Leonardo MR, Wu MK. Outcome of root canal treatment in dogs determined by periapical radiography and cone-beam computed tomography scans. J Endod 2009;35;723-726.

43. Andreasen JO. Luxation of permanent teeth due to trauma - A clinical and radiographic followup study of 189 injured teeth. Scand J Dent Res 1970;78:273-86.

44. Côrtes MIS, Bastos JV. Biological and clinical aspects of traumatic injuries to the permanent teeth. In: Estrela C. Endodontic Science. Artes Médicas, São Paulo, 2009. 954-1078.

45. Bueno MR, Estrela C, Granjeiro JM, Estrela MRA, Azevedo BC, Diogenes A. Cone-beam computed tomography cinematic rendering: clinical, teaching and research applications. Braz Oral Res 2021;35:e024.

46. Mazzi-Chaves JF, Camargo RV, Borges AF, Silva RG, Pauwels R, Silva-Sousa YTC, Sousa-Neto MD. cone-beam computed tomography in endodontics -State of the art. Current Oral Health Rep 2021;8:922.

Received: 22/10/2021

Accepted: 05/11/2021 